\title{
Moderation in Australia-Policy and Achievements
}

\section{CREINA STOCKLEY}

The Australian Wine Research Institute, Australia.

\begin{abstract}
Alcohol has been consumed in Australia since European settlement in 1788. In 1998, approximately $60 \%$ of Australians consumed an alcoholic beverage at least once per week. The effects of alcohol on the human body are dose dependent, where the harmful effects of alcohol are generally observed only when alcohol consumption exceeds moderate consumption levels of 30 to $40 \mathrm{~g}$ of alcohol per day. The discovery that a Jshaped curve described the relationship between level of alcohol consumption and risk of cardiovascular disease was, however, only made in 1990-cardiovascular disease is the leading cause of death in the western world. Thus prior to 1990, Australian public health policy focused primarily on the harmful effects of alcohol consumption and the health benefits of a moderate level of alcohol consumption have only recently been recognized in public policy. This paper chronicles changes in Australian Federal government policy on alcohol since the initial draft National health policy on alcohol in Australia was presented to the Ministerial Council on Drug Strategy in 1987 to the National Drug Strategic plan for action 2001 to 2003-2004 which was launched in July last year.
\end{abstract}

Key words: Alcohol, guidelines, moderation, moderation, policy, recommendation, wine.

Abbreviations: NH\&MRC: National Health and Medical Research Council.

\section{INTRODUCTION}

Alcohol is enjoyed and widely used in Australian society, associated with celebrations, business and social functions, and consumed in religious and cultural ceremonies. Although there has been an approximate $19 \%$ decline in per capita alcohol consumption over the past 20 years, by 1998, approximately $60 \%$ of Australians were consuming at least one alcoholic beverage per week (ABS, 1998; Stanford, 1999). The majority of the consumers drank on only one or two days per week, and only 1 to $2 \%$ of consumers drank daily (ABS, 1998; Stanford, 1999).

The statistics available on alcohol consumption are generally divided into low, medium and high risk of alcohol-related harm which corresponds to light, moderate and excessive alcohol consumption (National Health and Medical Research Council, 1987; Pols and Hawks, 1992; National Health and Medical Research
Council, 2001). By 1999, in Australia $80 \%$ of all drinking occasions were of low to medium risk of harm (ABS, 1998; Stanford, 1999), although $51 \%$ of total consumption occurred on days when the consumer exceeded low risk limits for acute harm (Stockwell et al., 2002). However, despite the general decline in alcohol consumption since 1982, alcohol consumption per se has increased among young Australians and often at a high-risk level. Accordingly, alcohol misuse is claimed to be second only to tobacco as a preventable cause of death and hospitalization in Australia (Collins and Lapsley, 1996; Chikritzhs, 1999). Principal among alcohol-related causes of death and hospitalization are cirrhosis of the liver, alcohol dependence, hemorrhagic stroke, suicide and motor vehicle accidents, such that the misuse of alcohol purportedly accounts for approximately $4.9 \%$ of the total disease burden in Australia (Mathers et al., 1999). This magnitude alone is indicative 
of the need for immediate governmental intervention, but although some alcohol consumption incurs costs, some alcohol consumption can also confer benefits. The beneficial health effects of alcohol consumption thus provide significant challenges for policy and reinforces the importance of promoting low risk consumption patterns.

This paper chronicles changes in Australian Federal government policy on alcohol since the initial draft National Health Policy on Alcohol in Australia was presented to the Ministerial Council on Drug Strategy in 1987. This policy was prepared in response to the Senate Standing Committee on Social Welfare stating, in 1977, that "alcohol problems in Australia had reached epidemic proportions, the neglect of which would represent gross national irresponsibility".

\section{National health policy on alcohol in Australia of 1989}

Thirteen years ago the stated overall objective of the previous National Health Policy on Alcohol in Australia was harm minimization. Harm minimization is the acceptance of alcohol consumption within the general community, but where strategies are designed to minimize the harms ensuing from that consumption, without necessarily reducing consumption. The strategies of the policy were, however, less related to harm minimization and more to population control or preventative paradox theory. The paradox was that people who typically consumed a moderate amount of alcohol and were considered at low risk of harm actually contributed the most harm because they were numerically greater (Kreitman, 1986). Correspondingly, less harm was contributed by the smaller number of heavy consumers at higher risk of harm (Kreitman, 1986). This was based on averaged or mean consumption over a week or month, for example, rather than on any one occasion.

Theoretically then, a greater reduction in alcohol-related harm within a community would be observed if all alcohol consumers were targeted to consume less, irrespective of their current level of consumption, than if only heavy consumers were targeted (Ledermann, 1965; Kreitman, 1986). Some of the strategies ensuing from this theory were primarily to prevent harm by reducing the availability of alcohol within a community, as it was considered that the risk of all harm was also directly related to mean level of consumption. While there is evidence of such a linear relationship for alcohol-related accidents, the relationship is exponential for cirrhosis of the liver, for example (McLean et al., 1980, Edwards et al., 1994). Furthermore, this theory implied that even moderate alcohol consumption was harmful.

Thus, one of the most serious and significant flaws in this theory, and hence in the National Health Policy on Alcohol in Australia of 1989, and the subsequent National Drug Strategic Plan 1993-1997, is the omission in the equation of any health benefit from light-to-moderate alcohol consumption, such as a reduction in the level and risk of cardiovascular disease and in overall mortality, which is evidenced in most, but not all, epidemiological studies, and is generally observed irrespective of gender, ethnicity and geography (Klatsky, 1990; Renaud and de Lorgeril, 1992; Klatsky and Armstrong, 1993; Maclure, 1993; Rimm et al., 1996; de Burgh, 1998; Hart et al., 1999; Renaud et al., 2004). Indeed, from the J-shaped curve ascribed to the relationship between level of consumption and risk of overall mortality, a light-to-moderate level of consumption with no occasions of heavy consumption, confers significantly more benefit than harm to health (Moore et al., 1986; Boffetta and Garfinkle, 1990; Klatsky et al., 1990; Marmot and Brunner, 1991). Indeed, a reduction in mean consumption levels may result in a greater proportion on the community missing out on the potential cardioprotective effects of low-to-moderate alcohol consumption (Holman, 1995; Holman and English, 1995). Cardiovascular disease is the leading cause of death in Australia at approximately $25 \%$ and regular low to moderate alcohol consumption can reduce its risk by up to 40 \% (Rimm et al., 1996; 2001). 
Subsequent reanalysis of the data supporting the preventative paradox theory have shown that when patterns of alcohol consumption, especially episodes of heavy consumption and intoxication are analyzed rather than just mean consumption levels, the preventative paradox disappears (Stockwell et al., 1996). Instead it has been shown that specific occasions of heavy consumption, usually by people who generally consume a light-to-moderate amount in low risk ways, result in most alcohol-related harms or problems. For example, in 1997, acute conditions, such as alcohol-related fatal road injuries, allied to occasional high-risk consumption accounted for 28 $\%$ of all alcohol-related deaths while chronic conditions, such as cirrhosis of the liver, allied to sustained high-risk consumption accounted for $42 \%$ of all alcohol-related deaths (Chikritzhs et al., 2001). Thus the pattern of alcohol consumption is as, if not more, predictive of harm than per capita consumption. Hence, a greater reduction of risk in the general community may be achieved through the prevention of heavy high-risk consumption occasions rather than by population control strategies to reduce mean consumption levels.

National health and medical research council recommendations of 1987 and 1992

Prepared in parallel with the initial draft National Health Policy on Alcohol in Australia (1987) were the National Health and Medical Research Council (NH\&MRC) recommendations regarding responsible drinking behavior, Is there a safe level of daily consumption of alcohol for men and women? (first published in 1987 and revised in 1992). The emphasis of these recommendations was consistent with that of the Policy that per capita consumption is directly associated with alcohol-related harms (Addiction Research Foundation, 1979; 1981; Rendell et al., 1983). Hence the recommendations themselves were cautious. They were primarily based on the risk of damage by alcohol on the body's organs and tissues, and the risk of death in the longer term, where 'safe' was related to an acceptable level of risk. The preparation of the 1987 recommendations was deemed appropriate by the Federal and State Departments of Health given that since 1975, the incidence of alcohol-related diseases, injuries and problems had significantly increased and impacted on the individual and the general community. Indeed, by 1983, $43 \%$ of years of life lost from drug use was associated with alcohol consumption. The basic recommendations were as follows:

- That the consumption of alcohol by men should not exceed 4 units or $40 \mathrm{~g}$ of absolute alcohol per day on a regular basis, or 28 units per week; and

- That the consumption of alcohol by women should not exceed 2 units or $20 \mathrm{~g}$ of absolute alcohol per day on a regular basis, or 14 units per week.

One unit, which is also referred to as a standard drink, represents $10 \mathrm{~g}$ of absolute alcohol or ethanol in Australia. For a $12 \%$ $\mathrm{v} / \mathrm{v}$ alcohol wine, one standard drink is approximately $100 \mathrm{~mL}$, where a $750 \mathrm{~mL}$ bottle of this wine would carry a comment stating that "This bottle contains approximately 7.5 standard drinks." For a $17-22 \% \mathrm{v} / \mathrm{v}$ alcohol fortified wine, such as a port or liqueur, one standard drink is approximately $60 \mathrm{~mL}$.

Australia's recommendations, however, have generally contrasted with those of other countries, in that both daily and weekly amounts were stated, which reflected consideration of both amount and pattern of consumption associated with risk of harm (Department of Health, 1995). Other countries' recommendations generally are expressed as amounts consumed per week indicating a preoccupation with the problems of regular consumption and dependence rather than those episodes of heavy consumption or intoxication.

The recommendations also defined 'safe', 'hazardous' and 'harmful' drinking levels, which are allied to levels of risk of alcohol-related harm. For example, two to four units per day or 14-28 units per week 
was considered 'hazardous' for women and more than four units per day or 28 per week was considered 'harmful' for women, while four to six units per day or 28-42 units per week was considered 'hazardous' for men and more than six units per day or 42 units per week was considered 'harmful' for men.

These defined levels were, however, based on a variety of scientific and social opinions rather than on a detailed review of the epidemiological research. Then in 1996, a meta-analysis was undertaken of 16 cohort studies which examined the relationship between the level of consumption and all-cause mortality, and a further 132 epidemiological studies were examined for 10 specific alcohol-associated causes of death, such as cardiovascular disease. The meta-analysis determined that the relative risks of mortality as defined in the recommendations were consistent with available epidemiological evidence (Holman et al., 1996). The meta-analysis also determined that a pattern of usual alcohol consumption consistent with the recommendations for 'safe' drinking levels would confer a mortality risk similar to or less than that observed in abstainers for people aged 35 years or older.

In addition, a recommendation was that all people should have two alcohol free days per week, and that pregnant women and people driving or operating machinery should abstain from alcohol.

\section{National alcohol strategy of 2001}

In 1997, an external review was undertaken of the policy and progress of the National Drug Strategy 1993-1997. The review revealed that in the community the mean level of alcohol consumption had declined since 1985 , but the proportion of consumers who drank alcohol heavily at least once per week had only declined by approximately 4 $\%$, and consumers who habitually drank heavily were resistant to change (Single and Rohl, 1997). Those consumers resistant to change included adolescent and young adult Australians and indigenous Australians, although the proportion of all Australians identifying alcohol as contributing to the 'drug' problem had significantly increased. In addition, while there was some community support for population control and prevention policies, most support was for strategies limiting alcohol advertising and the service of alcohol to inebriated consumers, and serving only low alcohol beverages at sporting events. Interestingly those consumers supporting the population control and prevention policies did not habitually drink heavily (ABS, 1996).

The main focus of the current National Alcohol Strategy-a plan for action 2001 to 2003-2004 is still harm minimization, but the focus of the strategies has shifted from alcohol consumption to consequences of use, conveying to consumers the concerns with the consequences of consumption. The strategies and objectives are also more focused to reduce the risk of and/or contain harm ensuing from consumption rather than to reduce the overall level of consumption of an individual or a community (Heather et al., 1993). This Strategy also recognizes that most at-risk consumption is ad hoc and irregular rather than associated with habitual heavy consumption (Stockwell et al., 1996) and hence that there is no definitive group of at-risk consumers that can be targeted (Cahalan and Room, 1974; Clark and Cahalan, 1976; Cherpitel, 1991; Tracy et al., 1992; Skog, 1993), apart from young-adults. Indeed in 1995, while approximately two thirds of Australian consumers drank alcohol at a hazardous level on one occasion, generally their consumption could be classified as 'safe' (McAllister, 1993; Single and Rohl, 1997), but the converse was observed for young adults. An objective is, therefore, to protect those individuals at higher risk of alcoholrelated harm as well as specifically preventing it in young adults, by focusing on at risk consumption patterns. Initial results from a classroom-based alcohol education program in Western Australia, which enables young adults to better identify and deal with high-risk consumption situations, suggests that such tailored programs can reduce harm in this high-risk group (McBride et al., 2000).

Altogether there are 11 key strategic areas, which include community education 
and information, specific workplace education, improved training for health professionals to aid early intervention and access to treatment, improved effectiveness of legislative and regulatory initiatives and drink driving initiatives, promotion of safer drinking environments and the responsible marketing and provision of alcohol, as well as the usual population control strategies of price and taxation. This Strategy also recognizes that non-traditional partnerships can be formed with all stakeholders including the alcohol beverage industry, to improve the capacity of individuals, families and the community to respond to alcohol-related harm.

In addition, for the first time in an Australian alcohol policy, a primary aim of the Australian National Drug Strategy-a plan for action 2001 to 2003-2004 is also to achieve a balance between reducing the burden of alcohol-related harm and maximizing the social and health benefits of low risk alcohol consumption.

\section{Australian alcohol guidelines of 2001}

An action issue from the National Drug Strategy-a plan for action 2001 to 20032004 is to inform the community about the NH\&MRC Australian Drinking Guidelines health risks and benefits of 2001, the premise of which is to enable individuals to discern high-risk consumption.

In 1999, the NH\&MRC began a review of their 1987 and 1992 recommendations, as more material was becoming available concerning the importance of drinking patterns and individual risk factors to the safe consumption of alcohol by men and women. Individual risk factors for alcohol-related harm include age, genetic variation in alcohol metabolism and susceptibility to certain diseases and disorders, and health status, as well as the amount of alcohol consumed on any one occasion. The differentiation between the level of alcohol that can be safely consumed by men and women, however, remains.

The Guidelines build on the 1987 and 1992 recommendations regarding responsible drinking behavior, and attempt to address when, where and under what circumstances hazardous consumption and associated high risk is likely to occur. As there are various alcohol consumption patterns, the reduction of this variety and complexity to a single measure of mean daily intake is likely to hide patterns of consumption that are particularly harmful, such as binge drinking.

Most importantly, however, these Guidelines are based on a detailed review of epidemiological and scientific research on alcohol and health. Briefly, the 12 recommendations of these Guidelines can be divided into general and specific.

The general recommendations for Australians define a level of alcohol consumption at which there is only minimal risk of harm, and where there may be some health benefits for a proportion of the general population. As evident in the Strategy, these guidelines recognize that alcohol consumption, at a low to moderate level, can have significant health benefits for some people, particularly in a reduction of the risk of cardiovascular disease from 'middle age' onwards. For example, these guidelines recommend that every person who drinks alcohol should control their pattern of drinking to minimize both longer-term and short-term risks, and to gain longer-term benefits.

For example, men should drink:

- Not more than 28 standard drinks per week, and those should be spread over 5 or 6 days; and

- Not more than an average of 4 standard drinks per day, and not more than 6 standard drinks on any one occasion and not more than 2 drinks in the first hour and 1 per hour thereafter, to minimize short-term risk within the weekly limit.

Women should drink:

- Not more than 14 standard drinks per week, and those should be spread over 5 or 6 days; and

- Not more than an average of 2 standard drinks per day, and not more 4 standard drinks on any one occasion and not more 
than 1 standard drink per hour, to minimize short-term risk within the weekly limit.

The specific recommendations relate to high-risk occasions, for particular groups in the community, such as different age groups, dependency, pregnancy, concurrent medication consumption and current abstainers of alcohol, and for private and public drinking environments.

\section{Future directions for policy}

In conclusion, as with any risk of illness, injury or death, the costs and benefits of a particular behavior such as alcohol consumption must be continually evaluated, as one progresses through life. An understanding of reasons for the risk, and an ability to assess the validity of each theory that evolves, will surely aid and guide any decision made by individuals on an appropriate level of alcohol consumption for their particular stage of life. The National Drug Strategya plan for action 2001 to 2003-2004 and Australian Drinking Guidelines health risks and benefits of 2001 accurately and adequately reflect the current knowledge and understanding of alcohol-related harms and, in particular, benefits to the Australian community per se. However, as more research results are generated and all the actions of this new Strategy are undertaken, evaluation becomes imperative to allow redefinement of the objectives and redevelopment of the specific strategies and recommendations. This is important to ensure that the community can continue to make fully informed decisions on alcohol consumption. An evaluation is actually the eleventh key strategic area of the new Strategy, and heralds another first for Australian government alcohol policy.

\section{DISCLAIMER}

The views expressed herein represent those of the author and not necessarily the Australian wine industry.

\section{ACKNOWLEDGMENT}

The position of Health and Regulatory Information Manager is supported by Australia's grapegrowers and winemakers through their investment body, the Grape and Wine Research and Development Corporation, with matching funds from the Federal government.

\section{REFERENCES}

A STRATEGY FOR THE PREVENTION OF ALCOHOL PROBLEMS (1979) Recommendations to the Ontario Parliament from the Executive Committee of the ARF. Addiction Research Foundation, Toronto

ALCOHOL, SOCIETY AND THE STATE (1981) A comparative study of alcohol control. Volume 1. Addiction Research Foundation, Toronto

ALCOHOL SUBCOMMITTEE OF THE MINISTERIAL COUNCIL ON DRUG STRATEGY (1987) Draft National Health Policy on Alcohol in Australia. Australian Government Publishing Service, Canberra

AUSTRALIAN BUREAU OF STATISTICS (1996) Unpublished preliminary results from the National Household Survey

AUSTRALIAN BUREAU OF STATISTICS (1998) Population Survey Monitor. Australian Government Printing Service, Canberra

BOFFETTA P, GARFINKLE L (1990) Alcohol drinking and mortality among men enrolled in an American Cancer Society prospective study. Epidemiology, 1: 342-348

CAHALAN D, ROOM R (1974) Problem drinking among American men. New Brunswuick NJ; Rutgers Center of Alcohol Studies

CHERPITAL CJS (1991) Drinking patterns and problems among primary care patients: a comparison with the general population. Alcohol and Alcoholism, 27: 627633

CHIKRITZHS T, JONAS H, STOCKWELL TR, HEALE P.F, DIETZE P.M (2001) Mortality and life-years lost due to alcohol: a comparison of acute and chronic causes. Medical Journal of Australia, 174: 281-284.

CHIKRITZHS T, JONAS H, HEALE P, DIETZE P, HANLIN K, STOCKWELL T (1999) National alcohol indicators. Report no.1. National Drug Research Institute, Perth, Western Australia

CLARK W, CAHALAN D (1976) Changes in problem drinking over a four-year span. Addictive Behaviours, 1: 251-259

COLLINS DJ, LAPSLEY HM (1996) The social costs of drug abuse in Australia in 1988 and 1992. Australian Government Printing Service, Canberra

DE BURGH SPH (1998) Modelling alcohol prevention policy. Paper presented at the Second International Conference on Drinking Patterns and Their Consequences, 1-5 February 1998; Perth, Australia

EDWARDS G, ANDERSON P (1994) Alcohol policy and the public good. Oxford University Press, Oxford, UK

HEATHER N (1993) In: Heather, N., Wodak, A., Nadelman, E., O'Hare, P. (ed). Psychoactive drugs and harm reduction: from faith to science. London, Whurr

HOLMAN C.DJ (1995) Analysis, action and the third creation of public health. Lecture form the Foundation 
Chair in Public Health of the University of Western Australia and a McNulty Oration of the Public Health Association of Australia. Perth, Queen Elizabeth II Medical Centre

HOLMAN C.DJ, ENGLISH DR, MILNE E, WINTER, MG (1996) Meta-analysis of alcohol and all-cause mortality: a validation of NHMRC recommendations. Medical Journal of Australia, 164: 141-145

HOLMAN C DJ, ENGLISH DR (1995) An improved aetiological fraction for alcohol-caused mortality. Australian Journal of Public Health, 19: 138-141

KENDELL RE, DE ROUMANIE M, RITSON EB (1983) Effect of economic changes on Scottish drinking habits. British Journal of Addiction, 78: 365-380

KLATSKY AL (1990) Alcohol and coronary artery disease. Alcohol Health and Research World, 14: 289300

KLATSKY AL, AMSTRONG MA, FRIEDMAN GD (1990) Risk of cardiovascular mortality in alcohol drinkers, ex-drinkers and nondrinkers. American Journal of Cardiology, 66: 1237-1242

KLATSKY AL, AMSTRONG MA (1993) Alcoholic beverage choice and risk of coronary artery disease mortality: do red wine drinkers fare best? American Journal of Cardiology 71: 467-469

KREITMAN N (1986) Alcohol consumption and the preventative paradox. British Journal of Addiction, 81: 353-364

LEDERMANN S (1956) Alcool, alcoolismes, alcoolisation. Volume 1. Paris: Presses Universitaires de France (Institut National d'Etudes Demographiques. Travaux et documents, Cahier 29: 41)

McLEAN A.J, HOLUBOWYCZ OT, SANDOW BL (1980) Alcohol and crashes: identification of relevant factors in this association. NH\&MRC Road Accident Research Unit, Report number CR 11

MACLURE M (1993) Demonstration of deductive metaanalysis: alcohol intake and risk of myocardial infarction. Epidemiology Reviews, 15: 328-351

MARMOT MG, BRUNNER E (1991) Alcohol and cardiovascular disease: the status of the U-shaped curve. British Medical Journal, 303: 565-568

MATHER C, VOS T, STEVENSON C (1999) The burden of disease and injury in Australia. Australian Institute of Health and Welfare, Canberra

McBRIDE N, MIDFORD R, FARRINDON F, PHILLIPS M (2000) Early results from a school alcohol harm minimization study: the School Health and Alcohol Harm Reduction Program. Addiction, 95: 1021-11042

MINISTERIAL COUNCIL ON DRUG STRATEGY SUBCOMMITTEE (1989) National health policy on alcohol in Australia and Examples of strategies for implementation. National Campaign Against Drug Abuse

MOORE RD, PEARSON TA (1986) Moderate alcohol consumption and coronary artery disease. Medicine, 65: $242-267$
NATIONAL HEALTH AND MEDICAL RESEARCH COUNCIL (NH\&MRC) (1987) Is there a safe level of daily consumption of alcohol for men and women? Australian Government Publishing Service, Canberra

NATIONAL DRUG STRATEGY COMMITTEE (1993) National Drug Strategic Plan 1993-1997. Australian Government Printing Service, Canberra

NATIONAL EXPERT ADVISORY COMMITTEE ON ALCOHOL (NEACA) (2001) National Alcohol Strategy: a plan for action 2001 to 2003-04. Commonwealth Department of Health and Aged Care, Canberra

NATIONAL ALCOHOL RESEARCH AGENDA (2002) Commonwealth Department of Health and Ageing, Canberra

PEQUIGNOT G, CHABERT C, EYDOUX H, COURCOUL MA (1974) Augementation du risqué de rhose en fonction de la ration d'alcool. Revue de l'Alcoolisme, 20: 191-202

POLS RG, HAWKS DV (1992) Is there a safe level of daily consumption for men and women? Second edition. Australian Government Printing Service, Canberra

RENAUD S, DE LORGERIL M (1992) Wine, alcohol and the French paradox for coronary heart disease. The Lancet 339: 1523-1526

RENAUD S, GUEGUEN R, CONARD P (2004) Alcohol and Mortality from All Causes. Biol Res 37: 183-187

RIMM E (2001) Alcohol and coronary heart disease: can we learn more? Epidemiology, 12(4): 380-382

RIMM EB, KLATSKY A, GROBBEE D, STAMPFER MJ (1996) Review of moderate alcohol consumption and reduced risk of coronary heart disease: is the effect due to beer, wine or spirits? British Medical Journal, 309: 911-918

SCOG OJ (1993) The tail of alcohol consumption distribution. Addiction, 88: 601-610

SENATE STANDING COMMITTEE ON SOCIAL WELFARE (1977) Australian Government Publishing Service, Canberra

SINGLE E, ROHL T (1997) The National Drug Strategy: mapping the future. An evaluation of the National Drug Strategy 1993-1997. A report commissioned by the Ministerial Council on Drug Strategy. Australian Government Publishing Service, Canberra

STANFORD L (1999) Observations on alcoholic beverage consumption. A paper presented to the 1999 Wine Industry Outlook Conference, Adelaide

STOCKWELL TR, HEALE P, CHIKRITZHS TN, DIETZE P, CATALANO P (2002) How much alcohol is drunk in excess of the new Australian alcohol guidelines? Medical Journal of Australia, 176: 92-93

STOCKWELL T, HAWKS D, LAND E, RYDON P (1996) Unraveling the preventative paradox for acute alcohol problems. Drug and Alcohol Reviews, 15: 7-15

TRACY JI, GORMAN DM, LEVENTHAL EA (1992) Reports of physical symptoms and alcohol use: findings from a primary care sample. Alcohol and Alcoholism, 27: 481-491 